\title{
Exploring food system policy: A survey of food policy councils in the United States
}

\author{
Allyson Scherb ${ }^{\text {a }}$, The Johns Hopkins Bloomberg School of Public Health \\ Anne Palmer', The Johns Hopkins Bloomberg School of Public Health Center for a Livable Future \\ Shannon Frattarolic, The Johns Hopkins Bloomberg School of Public Health \\ Keshia Pollack ${ }^{\mathrm{d} *}$, The Johns Hopkins Bloomberg School of Public Health
}

Submitted 18 August 2011 / Revised 30 December 2011 and 14 March 2012 / Accepted 29 March 2012 /

Published online 24 August 2012

Citation: Scherb, A., Palmer, A., Frattaroli, S., \& Pollack, K. (2012). Exploring food system policy: A survey of food

policy councils in the United States. Journal of Agriculture, Food Systems, and Community Development, 2(4), 3-14.

http://dx.doi.org/10.5304/jafscd.2012.024.007

Copyright (C) 2012 by New Leaf Associates, Inc.

\footnotetext{
a This research was conducted while Allyson Scherb was a master's of public health student at The Johns Hopkins Bloomberg School of Public Health.

Allyson Scherb is now at Health Resources in Action; 622 Washington Street; Boston, Massachusetts 02124 USA; ascherb@jhsph.edu

b The Johns Hopkins Bloomberg School of Public Health Center for a Livable Future; 615 North Wolfe Street, Suite W7010; Baltimore, Maryland 21205 USA; ampalmer@jhsph.edu

c Department of Policy and Management, The Johns Hopkins Bloomberg School of Public Health; 624 North Broadway Street, Room 545; Baltimore, Maryland 21205 USA; sfrattar@jhsph.edu
}

${ }^{\mathrm{d}}$ Department of Policy and Management, The Johns Hopkins Bloomberg School of Public Health; 624 North Broadway Street, Room 557; Baltimore, Maryland 21205 USA.

* Corresponding author: Keshia Pollack; +1-410-502-6272; kpollack@jhsph.edu

\begin{abstract}
Food policy councils (FPCs) have become a popular way to organize various food system stakeholders at the local, municipal, and state levels. FPCs typically build partnerships with stakeholders; examine current policies, regulations, and ordinances related to food; and support or create programs that address food system issues. While FPCs have the potential to affect policy change and often include policy-related goals in their missions, the literature on how FPCs engage in the policy process, what policies FPCs address, and the policy impacts of their work are very limited. We conducted an electronic survey of FPC leaders to describe FPCs, their level of engagement in policy processes, and the scope of their policy activities. We invited all U.S. FPCs that were included in an FPC database $(\mathrm{N}=92)$ to participate. Of the 56 FPCs that completed the survey (64 percent response rate), 52 percent had
\end{abstract}


been in existence for at least 3 years and 85 percent were engaged in policy activities at the time of the survey. Most FPCs engage in policy work in multiple venues ( 88 percent) and on multiple topics (79 percent). Many FPCs reported participating in the policy process through problem identification (95 percent) and education (78 percent); few mentioned evaluating their policy work. Those not engaged in policy most often cited lack of resources and technical expertise as barriers. These results suggest that while most FPCs are engaging in policy, why and how they engage varies greatly. Since FPCs are frequently cited as an effective way to address local and state food system issues, there is a need for more rigorous evaluation of the processes, outcomes, and impacts of their work.

\section{Keywords}

evaluation, food policy council, food system, policy

\section{Introduction}

Food has never figured so prominently on the public agenda as it does now. Recognizing the interdependence of hunger, malnutrition, dietrelated disease, agriculture, poverty and access to food, and economic development, food policy councils (FPCs) are being created to address multiple sectors of the food system (Harper, Shattuck, Holt-Giménez, Alkon, \& Lambrick, 2009). The first FPC was started in Knoxville in 1982, and the growing number of FPCs (from 50 or 60 North American FPCs in 2000 to approximately 150 in 2011 (M. Winne, personal communication, 2011)) reflects a trend that shows no sign of abating. FPCs take many forms, from local government entities to nonprofit organizations, and include representatives from different sectors of the food system. Their primary functions are "to serve as forums for discussing food issues; to foster coordination between sectors in the food system; to evaluate and influence policy; and to launch or support programs and services that address local needs" (Harper et al., 2009, p. 2). More simply stated, "Food policy councils offer a concrete example of a deliberate attempt to develop the practice of food democracy" (Hassanein, 2003, p. 79). FPCs provide a space for seemingly disparate sectors to develop relation- ships that lead to changes in food system policy. Given the increase in interest and subsequent resources dedicated to them, understanding how FPCs are addressing policy is of critical importance.

Food policy can be defined as "any decision made by a government agency, business, or organization which affects how food is produced, processed, distributed, purchased and protected" (Hamilton, 2002, p. 423). While federal food and agricultural policy has helped to create the current food system, state and municipal governments, and nonprofit organizations are examining their respective roles in changing policies at the institutional, local, regional, state, and federal levels to influence the food system (K. Clancy, personal communication, 2011). With the growth of FPCs around the country, as well as the sanctioning of many FPCs by local and state governments, they are positioned to contribute to this policy process, but more information about the work and impact of FPCs is needed.

Published research on FPCs is scant, leaving many gaps in knowledge as to their role in the policy process. Much of what is known about FPCs is based on several decades of work by a few food policy experts (Clancy, Hammer, \& Lippoldt, 2007; Dahlberg, 1994; Fiser, 2006; Lang, Rayner, Rayner, Barling, \& Millstone, 2004; Schiff, 2007; Winne, 2008). In "Food Policy Councils: Past, Present and Future," Dr. Clancy and colleagues describe the work of eight government-sanctioned state and local FPCs that were operational for at least three years (as of 2007), and concluded that these FPCs' policy activities were focused on advising and making recommendations to local and state government agencies. FPCs most frequently offered recommendations to local policy agencies and participated in creating comprehensive food policy plans designed to improve local food systems (Clancy et al., 2007). The degree to which these plans have been implemented is undocumented in the literature and may be related to each council's length of existence and/or efficacy.

In contrast to local FPCs, state FPCs are less numerous and are charged with a variety of tasks that promote the development of food policy for their states. These activities range from coordi- 
nating state agencies that affect food security to increasing state procurement of local foods. Connecticut is highlighted by both Clancy et al. (2007) and Winne (2008) as a model state FPC that was established in response to a state statute charging the council to "develop, coordinate, and implement a food system policy" (Connecticut General Assembly, 1997). The scope of this research by Clancy and Winne provides important foundational examinations of FPCs and their role in the policy process and sets the stage well for a more in-depth assessment of the range of topics and processes through which FPCs engage in policy.

Previous research has looked at the structures, processes, and outcomes of individual or small samples of FPCs. Two doctoral dissertations have taken more comprehensive views of the population of FPCs, though these have remained focused primarily on organizational structure, processes, and activities (Fiser, 2006; Schiff, 2007). One study of 13 FPCs revealed that 10 had previously engaged in policy or hoped to do so in the future. This study also found that many councils report spending time on programs rather than policy (Schiff, 2008). Several FPCs reported they were focusing on building their credibility and capacity before becoming more involved in policy formulation (Schiff, 2008). Schiff's research primarily focused on defining the mission or roles of FPCs (versus their specific policy activities) and investigating their organizational characteristics, "as a foundation for identifying what may lead to 'bestpractice' organizational structure and process in fulfilling these roles" (2007, p. vi).

The need for research on FPCs' efficacy has been cited repeatedly in the literature (Feenstra, 1997; Webb, Hawe, \& Noort, 2001). Aside from these aforementioned studies based on small samples, little evaluation research has been conducted on FPCs' engagement in policy processes. The complex, multisector work of FPCs makes evaluation difficult. Lack of data or evaluation procedures within individual councils may also hamper FPCs' abilities to monitor and evaluate their efforts in the food system. The difficulty of evaluating efforts for some FPCs may also be due to insufficient funding for evaluation and a lack of evaluation expertise. This lack of evaluation data limits the dissemination of information about effective FPCs and the strategies they use, and inhibits the planning efforts of groups interested in replication (Webb, Pelletier, Maretzki, \& Wilkins, 1998). Most recently, Food First, a national research and advocacy organization, has called for more research on the activities of FPCs: "As the momentum behind Food Policy Councils grows, there is a clear need to evaluate the effectiveness of councils in meeting their stated goals, and their broader effect on the food system as a whole" (Harper et al., 2009, p. 5).

As part of a larger study exploring FPC policy efforts in the U.S., we conducted an electronic survey of FPCs, which marks the first attempt to measure at a national level how FPCs work on policy issues. The purpose of the survey was to document the number of FPCs involved with policy, describe the scope of policy activities underway, and identify the barriers and facilitators to engaging in the policy process. The survey also informed case selection for a multiple case study that is part of a larger study of FPCs.

\section{Significance of this Research}

This study seeks to both fill a gap in the literature and provide information useful to FPCs and others engaging in food policy. The survey results describe both successes and challenges associated with FPCs' policy initiatives. As such, the findings offer empirical evidence that may help FPCs assess their role in the policy arena and make strategic decisions about which policy issues to focus on. With this information, FPCs can reallocate scarce resources to influence strategic planning and more effectively engage in the policy process. This research also has the potential to inform decisions about how FPCs and their funders think about the appropriate structures and processes for engaging in food system policy. Finally, this research may provide guidance for cities and states planning to undertake food system policy work.

\section{Methods}

This research is part of a larger multiple case study underway at the time of this writing. Due to the dearth of empirical data on FPC policy activities, 
we decided to analyze data separately from the first phase, the electronic survey. In this paper we present the findings from this survey.

\section{Population of U.S. Food Policy Councils}

In order to form our sample, we sought to identify all FPCs in existence in the U.S. as of January 2011. The list of eligible FPCs was assembled from several sources: the Community Food Security Coalition (CFSC) website (CFSC, 2011); a list of national food policy conference attendees; and the websites of individual FPCs. The CFSC maintains a list of FPCs in North America, 92 of which are in the U.S. This list was the primary source for identifying FPCs and was verified using the food policy conference attendee list and websites of individual FPCs. Two national food policy experts (K. Clancy and M. Winne), consultants to the Johns Hopkins Center for a Livable Future (CLF), reviewed the final list of FPCs for completeness.

\section{Survey Development}

The FPC survey was created through collaboration between the project investigators and two CLF food policy experts. Survey questions were based on the CFSC Evaluation Toolkit (CFSC, n.d.) and supplemented with questions applying specifically to this research. Out of this collaboration, a brief 12-question survey was developed to assess background information on FPCs, whether and how FPCs are engaging in the policy process, what barriers FPCs face in policy engagement, and in what policy activities and topics FPCs are engaging. Some questions about the types of policy activities in which FPCs were engaged and barriers to engaging in policy had predetermined close-ended responses; other questions had open-ended responses. For example, a question about policy issues and topics the FPC was working on at the time of the survey was open-ended.

For the purposes of this research we defined "policy" very broadly. A policy can be legislative, regulatory, or simply visionary (e.g., an internal policy that guides an organization's actions), and can be made at any level — institutional, local, county, regional, state, or federal (Peters Moschetti, 2010).

\section{Survey Administration}

The CFSC list of FPCs includes an email address for the primary contact. Using this publicly available contact information, we emailed each FPC a brief message explaining the research and the purpose of the survey and included a link to the survey using Survey Monkey (2011). The survey was administered from March 7, 2011, to April 7, 2011. After one week, we re-sent the email to those who had not responded. A third and final reminder was sent one week later. Once respondents completed the survey, we contacted them only if clarification about their responses was needed.

Consistent with the collaborative nature of the food policy community, we found that several individuals were involved with multiple FPCs. This led to individuals responding in a single survey on behalf of more than one FPC. When this occurred, we asked the respondent to retake the survey and represent a single FPC. Separate representatives of the other FPCs were contacted to respond on behalf of these FPCs. Ultimately, two responses were discarded because we were unable to secure separate responses for the individual FPCs (these two respondents represented seven FPCs).

\section{Data Analysis}

Data were downloaded from Survey Monkey and analyzed in Excel using descriptive statistical techniques. Limited data were available for both the entire population of FPCs and the sample surveyed. Thus, in assessing the representativeness of the sample of FPCs included in the survey relative to the entire population of FPCs, we were only able to compare measures pertaining to geographic distribution (Northeast, South, Midwest, or West) and geographic area served (city, county, region or, state). Analyses of open-ended responses included review of the text, followed by organization of responses into similar categories by one of the authors. Two other co-authors reviewed these results and confirmed the original organization scheme. 


\section{Results}

\section{Sample}

Of the 92 representatives from FPCs we invited to participate, 56 responded to the survey for a response rate of 61 percent. One respondent started but did not complete the survey. Of the survey invitations sent, six bounced back and two respondents opted out. Efforts were made to obtain contact information for other individuals associated with these eight FPCs and when such information was identified, we sent additional invitations that yielded four completed surveys, which were included in our final sample of 56. Geographic characteristics of FPC survey respondents were compared to the total population of FPCs in terms of geographic distribution and geographic area served. Survey respondents represented 67 percent of existing FPCs in the West and 79 percent in the Northeast. Fifty-four percent of FPCs in the Midwest and 47 percent of FPCs in the South were included among respondents. Fifty-three percent of FPCs serving cities responded to the survey as well as 56 percent of state FPCs. Additionally, county and regional FPCs were overrepresented in the survey sample. The initial list of FPCs from the CFSC identified seven FPCs that served a regional area. However, 13 survey respondents identified themselves as responding for regional FPCs.

\section{Characteristics of FPCs}

Table 1 displays characteristics of FPCs in the survey sample. FPCs are located throughout the U.S., although the highest concentrations are in the Midwest and West, particularly California. FPCs typically serve one geographic area, such as a city or state. Fifty of the 56 survey respondents reported that they serve one geographic area. However, several FPCs represent multiple geographic areas, most often a county FPC serving the county as a whole as well as its constituent municipalities.

Nearly 50 percent of FPCs surveyed have been in existence for three or fewer years, with nine FPCs being formed in the last year. Two FPCs reported they intend to last no more than three years, while fifty-four have no set date for termination.
Seventy percent of the FPCs surveyed reported that they engage in some kind of data collection and/or evaluation, though many conceded that they have yet to start evaluation activities. Specific data collection and/or evaluation efforts described range from process evaluations and case studies to community food assessments and food system impact evaluations. Several FPCs that receive grant

Table 1. Description of Sample of FPCs $(N=56)$

\begin{tabular}{|c|c|}
\hline Geographic Distribution & $\mathrm{n}(\%)$ \\
\hline Northeast & $11(20 \%)$ \\
\hline South & $9(16 \%)$ \\
\hline Midwest & $14(25 \%)$ \\
\hline West & $22(39 \%)$ \\
\hline \multicolumn{2}{|l|}{ Geographic Area Served ${ }^{a}$} \\
\hline City & $18(32 \%)$ \\
\hline County & $24(43 \%)$ \\
\hline Region & $13(23 \%)$ \\
\hline State & $10(18 \%)$ \\
\hline \multicolumn{2}{|l|}{ Length of Existence } \\
\hline$<1$ year & $9(16 \%)$ \\
\hline $1-3$ years & $18(32 \%)$ \\
\hline$>3$ years & $29(52 \%)$ \\
\hline \multicolumn{2}{|l|}{ Intended Length of Existence } \\
\hline$<1$ year & $1(2 \%)$ \\
\hline $1-3$ years & $1(2 \%)$ \\
\hline No set date for termination & $54(96 \%)$ \\
\hline \multicolumn{2}{|l|}{ Evaluation of Policy Work } \\
\hline Yes & $11(20 \%)$ \\
\hline No & $45(80 \%)$ \\
\hline \multicolumn{2}{|l|}{ How People Become Members of FPCs ${ }^{a}$} \\
\hline Self-selecting & $35(63 \%)$ \\
\hline Nominated and voted in by FPC & $14(25 \%)$ \\
\hline Appointed by someone in authority & $15(27 \%)$ \\
\hline Other & $6(11 \%)$ \\
\hline \multicolumn{2}{|l|}{ Does FPC Engage in Policy Work? } \\
\hline Currently work on policy & $48(86 \%)$ \\
\hline Worked on policy in the past & $5(9 \%)$ \\
\hline Never worked on policy & $3(5 \%)$ \\
\hline
\end{tabular}


funding stated that they have specific process and outcome measures required by their funders. Overall, 11 of 56 FPCs surveyed ( 20 percent) mentioned evaluation related to policy efforts.

\section{FPCs and Policy Activities and Challenges}

As the name suggests, 86 percent $(n=48)$ of FPC respondents reported that they are currently working on policy. Those FPCs not working on policy cited challenges around defining priorities, lacking leadership, and not being allowed to undertake policy work because of their government affiliation. Of the respondents who are working on policy, there was not a uniform definition of what constitutes policy, and several FPCs mentioned that they had not defined policy for themselves. Some FPCs viewed policy as formal, public decisions that include laws, ordinances, guidelines, and official statements made by government entities. One respondent, citing Winne's definition, defined policy as "any government action or inaction." Other FPCs described policy as "the way business is done," and include organizational and community practices and procedures.

Most FPCs are engaging in policy at multiple levels, from institutional and city policy to state and federal policy. Table 2 shows at what levels FPCs were engaging in policy at the time they completed the survey.

FPCs are primarily engaging in policy at the local, institutional, and county levels. Most FPCs in our sample reported representing cities and counties. Thus, our respondents' policy work most often focuses at the city or county level, although

\section{Table 2. Levels of Policy Work at Which FPCs} Engage $^{a}$

\begin{tabular}{ll}
\hline City & $\mathbf{n}(\%)$ \\
\hline Institutional (e.g., schools, private sector) & $37(74 \%)$ \\
\hline County & $33(66 \%)$ \\
\hline State & $33(66 \%)$ \\
\hline Federal & $26(52 \%)$ \\
\hline Regional & $17(34 \%)$ \\
\hline
\end{tabular}

${ }^{a}$ Answers are not mutually exclusive, so total is greater than 100 percent. the levels are not mutually exclusive. Institutions are another major area of focus for FPCs, with schools being the predominant institutional venue reported.

The ways FPCs engage in policy vary from council to council, yet there are some activities in which most FPCs are involved. Table 3 lists the policy activities in which FPCs are engaged, based on their selection of closed-ended options. The survey question asked how each FPC engages in policy and listed the options shown in table 3.

Almost all FPCs responded that they identify problems that could be addressed through policy, and more than three fourths of FPCs educate the public about food policy issues. Fewer FPCs, though still significant percentages, engage more actively in policy by developing policy proposals (62 percent), lobbying for specific legislation (48 percent), and participating in the regulatory process (34 percent).

Through these policy activities, FPCs engage in a range of policy-related topics across all sectors of the food system, including production, purchasing, distribution, and consumption. Open-ended responses to two questions reveal past and current policy initiatives of the responding FPCs. We grouped these responses into similar categories

\section{Table 3. Types of Policy Activities in Which FPCs Engage $^{a}$}

\begin{tabular}{lr}
\hline & $\mathbf{n}(\%)$ \\
\hline $\begin{array}{l}\text { Identify problems that could be addressed } \\
\text { through policy }\end{array}$ & $47(94 \%)$ \\
\hline Educate public about food policy issues & $39(78 \%)$ \\
\hline Develop policy proposals & $31(62 \%)$ \\
\hline Lobby for specific proposals & $24(48 \%)$ \\
\hline Participate in the regulatory process & $17(34 \%)$ \\
\hline $\begin{array}{l}\text { Endorse other organizations' or institutions' } \\
\text { policies }\end{array}$ & $16(32 \%)$ \\
\hline \begin{tabular}{l} 
Implement policies \\
\hline $\begin{array}{l}\text { Other (including general food system } \\
\text { advocacy, formation of coalitions, and } \\
\text { provision of expert testimony to decision- } \\
\text { makers) }\end{array}$
\end{tabular} \\
\hline
\end{tabular}

a Answers are not mutually exclusive, so total is greater than 100 percent. 
Table 4. Responses to: If You Worked on Policies in the Past, Please Specify, and What Two Policies Are You Working On?

\begin{tabular}{|c|c|c|c|}
\hline Subject of Policy Effort & $\begin{array}{l}\text { Number of Past } \\
\text { Policies Reported } \\
\text { by } 22 \text { Respondents }\end{array}$ & $\begin{array}{l}\text { Number of Current } \\
\text { Policies Reported } \\
\text { by } 48 \text { Respondents }\end{array}$ & Examples of Responses \\
\hline Access to Food & 9 & 15 & $\begin{array}{l}\text { Policies that promote access to healthy, local foods for } \\
\text { school children, low-income people, farm workers, and } \\
\text { people living in food deserts. }\end{array}$ \\
\hline Agriculture & 8 & 15 & $\begin{array}{l}\text { Policies that promote urban agriculture, land } \\
\text { preservation, and reject GMO use. }\end{array}$ \\
\hline Procurement & 4 & 16 & $\begin{array}{l}\text { Policies that mandate the source of food purchased by } \\
\text { schools, hospitals, government, and universities. }\end{array}$ \\
\hline Animals & 5 & 6 & $\begin{array}{l}\text { Policies that permit chickens and bees to be raised in } \\
\text { urban areas. }\end{array}$ \\
\hline Community Gardens & 1 & 10 & $\begin{array}{l}\text { Policies that support gardens in the community, } \\
\text { including schools. }\end{array}$ \\
\hline Food Planning & 7 & 4 & $\begin{array}{l}\text { Policy efforts to promote county food charters, local } \\
\text { sustainable agriculture generally, county food plans, } \\
\text { and food policy councils. }\end{array}$ \\
\hline Farmers' Markets & 2 & 7 & $\begin{array}{l}\text { Policies that facilitate access to farmers' markets } \\
\text { through SNAP/EBT use, and access by low-income } \\
\text { people. }\end{array}$ \\
\hline Policy Analysis & 3 & 6 & $\begin{array}{l}\text { Efforts to assess existing policies and the need for } \\
\text { additional policies. }\end{array}$ \\
\hline Small Business Support & 2 & 6 & $\begin{array}{l}\text { Policies that promote small businesses, including } \\
\text { farmers and retailers. }\end{array}$ \\
\hline $\begin{array}{l}\text { Other (policies with fewer } \\
\text { than five responses to } \\
\text { either question) }\end{array}$ & 5 & 11 & $\begin{array}{l}\text { Policies that include food assistance, trans fat bans, } \\
\text { promoting composting, addressing the emergency food } \\
\text { supply, menu labeling, budget decision-making around } \\
\text { food, and federal bills. }\end{array}$ \\
\hline Total & 46 & 96 & \\
\hline
\end{tabular}

(table 4). The 22 respondents who specified past policies with which their FPCs were involved described 46 policy efforts. (Seven additional respondents provided answers that were not specific enough to be categorized, such as, "we specifically focus on policy level efforts.") More than half of these policies sought to increase access to local and/or healthy foods; promote agriculture; and encourage state and municipal food planning efforts. When asked to identify two policies they were working on at the time of the survey, 48 respondents (100 percent of those indicating they were engaging in policy work at the time of the survey) answered this open-ended question with enough detail to categorize. Most of the policies described sought to influence institutional food purchasing policies of schools, hospitals, and governments; improve access to local and/or healthy foods; promote agriculture; and support community gardens. Other policy topics detailed as part of past and present policy efforts are detailed in table 4.

We were also interested in understanding whether the policies aimed to change the physical food environment and/or individual behaviors. Of those policies for which we could discern the target of influence (117 of the 142 identified as past or current policy initiatives), all but two sought some type of institutional change that would affect the food environment and facilitate access to local and/or healthy food. For example, procurement policies aim to change the food that large institutions buy on behalf of the populations they serve. By supplying their kitchens with locally sourced 
food, the target institution will alter the food environment in which their employees and clients make their food choices. Many of the institutions targeted have captive audiences, such as schools, hospitals, and prisons, and so the institution provides those people with their available food choices.

Another type of environmental change policy is that which changes the environment in order to encourage individuals to engage the food system differently. Examples of such policies include those related to agriculture, community gardens, and farmers' markets that look to government to expand the range of production and distribution options available for people to grow crops, raise livestock, and sell the food that results from these efforts. By allowing an expansion of the ability to generate a local, healthy food supply, these policies have the potential to alter the food environment in ways that will improve access to healthy foods for residents. The two policies that did not fit within this category of changing the physical food environment sought support for public education and efforts to increase WIC enrollment.

Many of the FPCs included in our survey were working on urban agriculture issues, likely a reflection of where the FPCs were located geographically. However, many urban FPCs also work on issues that transcend urban/rural lines. These include farm-to-institution policies and general work on the farm bill, as well as issues concerning school food policy and farmers' markets. Additionally, several FPCs mentioned their work on cropland policy to preserve open space and agricultural land preservation, for example conservation easements for preservation of high quality soils.

While most FPCs are currently engaging in policy on multiple topics and multiple levels, they face a variety of challenges to their involvement in policy work. As shown in table 5,76 percent of respondents cite lack of time, 66 percent report lack of financial support for policy work, and 46 percent say lack of training or skills are barriers to engaging in the policy process. Other barriers to engaging in policy work mainly relate to challenges with government and challenges with FPC members. Government barriers include incon- sistent government support of FPC activities, lack of members' trust of government, and discouragement of government employees taking positions on policy issues. Additionally, several FPCs mentioned that their members represent a diverse network of stakeholders and often have differing positions on specific policies and differing abilities to engage in policy.

From this list of barriers, one might hypothesize that the more established FPCs would have greater success in influencing policy because of their experience. Therefore, we explored FPCs' policy activities based on how long they had been in existence. Prior work by Clancy et al. (2007) explored FPCs that had been in existence for at least three years; thus, we also analyzed the councils' policy activities comparing those in existence for less than three years to those in existence for three years or more (table 6 ). The FPCs surveyed, regardless of length of existence, generally work at the same levels of policy, engage in the same policy activities, and face the same barriers to policy work. However, there are a few notable exceptions when comparing newly formed FPCs to long-standing FPCs. FPCs that have been in existence longer (three or more years) report working on federal policy issues more than newer FPCs. In terms of type of policy activities (in other words, how FPCs engage in policy), there are differences between those FPCs that have been around more than three

\section{Table 5. Barriers to FPC Involvement in Policy Work ${ }^{\mathrm{a}}$}

\begin{tabular}{lc}
\hline & $\mathbf{n}(\%)$ \\
\hline Lack of time & $38(76 \%)$ \\
\hline Lack of financial support for policy work & $33(66 \%)$ \\
\hline $\begin{array}{l}\text { Lack of training or skills in how to engage in } \\
\text { the policy process }\end{array}$ & $23(46 \%)$ \\
\hline $\begin{array}{l}\text { Other (including lack of trust in government, } \\
\text { inconsistent support of government, and }\end{array}$ & $14(28 \%)$ \\
$\begin{array}{l}\text { differences of opinion across sectors of the } \\
\text { food industry on how to approach policy) }\end{array}$ \\
\hline \begin{tabular}{ll} 
Concern about violating nonprofit tax status & $4(8 \%)$ \\
\hline Policy is not a priority & $1(2 \%)$ \\
\hline
\end{tabular}
\end{tabular}

a Answers are not mutually exclusive, so total is greater than 100 percent. 
years compared to FPCs newer than three years. Newer FPCs develop more of their own policy proposals and participate in the regulatory process. Older FPCs engage in problem identification,

Table 6. Policy Work by FPCs' Length of Existence

\begin{tabular}{|c|c|c|}
\hline & $\begin{array}{c}\text { Less than } \\
3 \text { Years } \\
(n=27)\end{array}$ & $\begin{array}{c}3 \text { Years } \\
\text { or More } \\
(n=29)\end{array}$ \\
\hline Level of Policy Work & n (\%) & $\mathrm{n}(\%)$ \\
\hline Institutional & $15(56 \%)$ & $18(62 \%)$ \\
\hline City & $18(67 \%)$ & $19(66 \%)$ \\
\hline County & $16(59 \%)$ & $17(59 \%)$ \\
\hline State & $11(41 \%)$ & $15(52 \%)$ \\
\hline Federal & $6(22 \%)$ & $11(38 \%)$ \\
\hline Regional & $6(22 \%)$ & $5(17 \%)$ \\
\hline \multicolumn{3}{|l|}{ Policy Activities } \\
\hline $\begin{array}{l}\text { Identify problems that could } \\
\text { be addressed through policy }\end{array}$ & $21(78 \%)$ & $26(90 \%)$ \\
\hline $\begin{array}{l}\text { Educate public about food } \\
\text { policy issues }\end{array}$ & $17(63 \%)$ & $22(76 \%)$ \\
\hline Develop policy proposals & $17(63 \%)$ & $15(52 \%)$ \\
\hline Lobby for specific proposals & $11(41 \%)$ & $13(45 \%)$ \\
\hline $\begin{array}{l}\text { Participate in the regulatory } \\
\text { process }\end{array}$ & $10(37 \%)$ & $7(24 \%)$ \\
\hline $\begin{array}{l}\text { Endorse other organizations' } \\
\text { and institutions' policies }\end{array}$ & $3(11 \%)$ & $13(45 \%)$ \\
\hline Implement policies & $6(22 \%)$ & $5(17 \%)$ \\
\hline
\end{tabular}

Barriers to Engaging in Policy

Work

\begin{tabular}{lcc}
\hline Lack of time & $14(52 \%)$ & $24(83 \%)$ \\
\hline $\begin{array}{l}\text { Lack of financial support for } \\
\text { policy work }\end{array}$ & $14(52 \%)$ & $19(66 \%)$ \\
\hline $\begin{array}{l}\text { Lack of training or skills in } \\
\text { how to engage in the policy } \\
\text { process }\end{array}$ & $8(30 \%)$ & $15(52 \%)$ \\
\hline $\begin{array}{l}\text { Other (including lack of trust } \\
\text { in government, inconsistent } \\
\text { support of government, and } \\
\text { differences of opinion across } \\
\text { sectors of the food industry } \\
\text { on how to approach policy) }\end{array}$ & $3(11 \%)$ & $10(34 \%)$ \\
\hline $\begin{array}{l}\text { Concern about violating } \\
\text { nonprofit tax status }\end{array}$ & $0(0 \%)$ & $4(14 \%)$ \\
\hline Policy is not a priority & $0(0 \%)$ & $1(3 \%)$ \\
\hline
\end{tabular}

a Answers are not mutually exclusive, so total is greater than 100 percent. public education, and most significantly endorse others' policies more frequently than newer FPCs. Barriers to policy engagement cited by longerstanding FPCs emphasize lack of time and training or skills for engaging in the policy process.

\section{Discussion}

Though the number of FPCs continues to grow, research on FPCs remains limited, leaving several gaps in the literature that this study seeks to fill. Prior research has examined a handful of local and state FPCs, focusing on organizational structure and processes (Clancy et al., 2007; Dahlberg, 1994; Harper et al., 2009; Winne, 2008). All these authors acknowledge the limited scope of their work and call for more research evaluating the outcomes and impacts of FPCs. Our research is one of the few studies to examine the entire population of FPCs in the U.S. and the only study, to our knowledge, that specifically examines how FPCs are engaging in the policy process. Although 70 percent of responding FPCs report some kind of data collection and evaluation effort of their work in general, both the variety of survey responses and the literature suggest a need for more systematic, rigorous evaluation of the FPCs work specifically in the policy arena. As more FPCs have emerged, organizations such as the Community Food Security Coalition and the United States Department of Agriculture (USDA) have created tools for FPCs to evaluate their work (CFSC, n.d.). ${ }^{1}$

Our results suggest that most of the FPCs we surveyed are engaging in policy work. FPCs were asked to define policy as they understood it, and our results show that many FPCs do not share a common definition of policy, and instead operate under individual working definitions that govern their activities. While the definitions for food policy vary, we found consistency in the types of policies that FPCs focus on. These include procurement (i.e., local food sourcing by institutions), agriculture (e.g., land preservation, urban agriculture) and access to healthy food (i.e., access in underserved areas), followed by community

\footnotetext{
${ }^{1}$ The CFSC reported in August 2012 that it will cease its operations by the end of 2012 . http:// foodsecurity.org/important-message-from-cfsc/
} 
gardening, food planning, farmers' markets, animal ordinances, and small business support. We found that these policy topics that seek to change the physical food environment were represented among both current and previous FPC policy activities, thus suggesting possible policy topics that newer FPCs also may want to explore. These common areas of policy focus, and the strategy of pursuing policies that aim to change the physical environment, may also suggest topics on which future evaluations can focus.

The primary policy activities FPC respondents noted are identifying issues that could be addressed through policy, and educating the public about food policy issues. While there are many explanations, these indirect forms of policy work may be the result of a lack of time or financial resources to engage in more direct, time-consuming policy work, lack of skills (46 percent reported the lack of skills as a barrier), or a lack of clarity about laws governing tax-exempt organizations and public employees (a concern reported by less than 10 percent of respondents). Resources to inform both of these latter issues are available, such as policy training and technical assistance by the CFSC, and efforts to assure that FPC leaders have access to them and that these resources are understood by and relevant to FPCs may help to address these barriers. In spite of the challenges identified by respondents, many FPCs reported developing policy proposals and engaging in efforts to support ongoing policy efforts. Although this study generated critical information not previously reported, more research is needed to better understand how FPCs engage in policy and what challenges they face in their policy work.

As discussed, FPCs organized within government agencies face particular challenges to engaging in the policy process. Inconsistent support for the FPC and lack of understanding of food system issues by their host agencies were two challenges cited by respondents who experience this barrier. Additional research is also needed on how FPCs are situated within the communities they represent and serve. Similarly, it would be helpful to know if and how nongovernmental FPCs engage in policy and whether their independence facilitates or hampers efforts to change policy.
Based on the challenges to policy engagement expressed by the FPCs, a need exists for more training and skill development focusing on how to participate in the policy process. Additionally, lack of time and staff were frequently cited as barriers. More explicit discussion within FPCs and prioritization of policy work could help FPCs direct time and resources to fulfilling their mission of improving food system policy. Support for staff time from funding agencies that is targeted at policy advocacy may help to focus FPCs' resources on policy.

Length of existence does not seem to indicate significant differences in FPCs' policy engagement. Long-standing FPCs tend to work more on policy at the federal level and engage in more indirect policy activities, such as endorsing the policies of other salient organizations. Our survey was not designed to fully capture these differences and future research could benefit from further exploration of the influence of length of existence on FPC policy-related activities.

Thirty-four percent of FPCs reported that they are working on policy at the federal level. This may reflect nationwide advocacy regarding the 2012 Farm Bill or the recent Child Nutrition Reauthorization law. The CFSC organizes FPCs around these issues and provides forums for discussion and avenues for action. From federal food assistance and zoning for urban agriculture to infrastructure development for poultry processing and school lunch programs, FPCs play a role in shaping many aspects of the U.S. food system. Assuring these efforts are effectively harnessed to maximize the potential of FPCs is a challenge we hope this research and future studies will help guide.

\section{Study Limitations}

These findings should be considered in light of some limitations. Specifically, nonresponse bias and the nature of self-report are of concern. While we engaged in several strategies to invite a comprehensive response, there are FPCs that did not participate and policy efforts that we likely missed. FPCs form and disband routinely, making it difficult to identify and connect with every one at any point in time. We identified 92 FPCs that were operational at the time we fielded our survey, of which 56 responded. It is unclear what the reasons 
are for nonresponders, though possible causes include lack of time, lack of interest in the topic, lack of incentive for taking the survey, and survey fatigue. Thus, our sample, while it includes a majority of identified FPCs, does not represent all of them.

The survey data provide a cross-sectional view as opposed to an historical or longitudinal view, which is difficult given the high turnover (short lifespan) of some FPCs. To address some of these limitations and further the research on policy engagement of FPCs, we are conducting a multiple case study of select FPCs and their policy work. This will allow for a more in-depth examination of the policy efforts of a small group of FPCs.

\section{Conclusion}

Most FPCs are currently working to effect policy change at multiple levels, on multiple topics, and through multiple activities. In part because of the lack of resources for policy work and the need for greater policy skills, the policy activities of FPCs tend toward more indirect activities, such as problem identification and education. Support for FPC policy work, in the form of both technical assistance and grant support, will likely be needed in order to accomplish a higher level of direct engagement with the policy process.

The findings of this research suggest there is a need for more systematic, rigorous evaluation of the processes, outcomes, and impacts of FPCs' policy work. These results, combined with ongoing data collection for the multiple case study, will generate additional and important information regarding how FPCs engage in the policy process, the facilitators and barriers they face, and the outcomes and impacts of their policy work.

Food policy councils have been in existence for the past 30 years, with a noticeable surge in activity during the past 10 years. As our food system becomes more complex and as the public and politicians realize the importance of food to our nation's health and sustainability, FPCs will continue to emerge and serve as vehicles for influencing food system policy. It is important that such efforts are informed by empirical evidence, which this research is the first to provide.

\section{Acknowledgements}

This publication was supported by a directed research grant from the Johns Hopkins Bloomberg School of Public Health Center for a Livable Future. The authors express appreciation to Dr. Kate Clancy and Mr. Mark Winne, visiting scholars at the Center for a Livable Future, for their invaluable guidance throughout this research, and for their helpful comments on this paper. The authors also thank each of the food policy councils that participated in the survey.

\section{References}

Clancy, K., Hammer, J., \& Lippoldt, D. (2007). Food Policy Councils: Past, present and future. In C. C. Hinrichs \& T. A. Lyson (Eds.), Remaking the North American Food System: Strategies for Sustainability (pp. 121-143). Lincoln, Nebraska: University of Nebraska Press.

Community Food Security Coalition [CFSC]. (n.d.). Evaluation program materials. Retrieved February 8, 2011, from http://www.foodsecurity.org/ evaluation pg2.html

Community Food Security Coalition [CFSC]. (2011). List of Food Policy Councils in North America. Retrieved March 2, 2011, from http://www.foodsecurity.org/ FPC/council.html

Connecticut General Assembly. (1997). Public Act 9711, Section 21: An act establishing a statewide food policy council under the auspices of the Department of Agriculture. http://www.cga.ct.gov/2011/pub/chap438d.htm

Dahlberg, K. (1994, June 11). Food Policy Councils: The experience of five cities and one county. Paper presented at the Joint Meeting of the Agriculture Food and Human Values Society and the Association for the Study of Food and Society, Tucson, Arizona.

Feenstra, G. W. (1997). Local food systems and sustainable communities. American Journal of Alternative Agriculture, 12, 28-36. http://dx.doi.org/10.1017/S0889189300007165

Fiser, D. (2006). Democratic food: Food Policy Councils and the rebuilding of local agriculture (Unpublished doctoral dissertation). University of Chicago, Chicago, Illinois.

Hamilton, N. D. (2002). Putting a face on our food: How state and local food policies can promote the new agriculture. Drake Journal of Agricultural Law, 7(2), 408-454. 
Harper, A., Shattuck, A., Holt-Giménez, E. Alkon, A., \& Lambrick, F. (2009). Food Policy Councils: Lessons learned (Development Report 21). Oakland, California: Food First/Institute for Food and Development Policy. Retrieved from http://www.foodfirst.org/en/foodpolicycouncilslessons

Hassanein, N. (2003) Practicing food democracy: A pragmatic politics of transformation. Journal of Rural Studies, 19(1), 77-86.

http://dx.doi.org/10.1016/S0743-0167(02)00041-4

Lang, T., Rayner, G., Rayner, M., Barling, D., \& Millstone, E. (2004) Discussion paper: Policy Councils on food, nutrition and physical activity: the UK as a case study. Public Health Nutrition, 8(1), 11-19. http://dx.doi.org/10.1079/PHN2005654

Peters Moschetti, W. (2010). Food policy blueprint. Retrieved April 24, 2011, from the LiveWell Colorado website: http://www.livewellcolorado.org Schiff, R. (2007). Food Policy Councils: An examination of organisational structure, process, and contribution to alternative food movements (Doctoral dissertation). Murdoch University, Perth.

Schiff, R. (2008). The role of Food Policy Councils in developing sustainable food systems. Journal of Hunger and Environmental Nutrition, 3(2), 206-228. http://dx.doi.org/10.1080/19320240802244017

Survey Monkey (2011). Survey Monkey. Retrieved April 24, 2011 from http://www.surveymonkey.com

Webb, K., Hawe, P., \& Noort, M. (2001) Collaborative intersectoral approaches to nutrition in a community on the urban fringe. Health Education and Behavior, 28, 306-319. http://dx.doi.org/10.1177/109019810102800305

Webb, K., Pelletier, D., Maretzki, A., \& Wilkins, J. (1998). Local food policy coalitions: Evaluation issues as seen by academics, project organizers, and funders. Agriculture and Human V alues, 15, 65-75. http://dx.doi.org/10.1023/A:1007408901642

Winne, M. (2008). Closing the food gap. Boston, Massachusetts: Beacon Press. 